\title{
Multi-Environment Evaluation and Genotype $\times$ Environment Interaction Analysis of Sorghum [Sorghum bicolor (L.) Moench] Genotypes in Highland Areas of Ethiopia
}

\author{
Amare Seyoum, Zigale Semahegn, Amare Nega, Sewmehone Siraw, Adane Gebreyohannes, \\ Hailemariam Solomon, Tokuma Legesse, Kidanemaryam Wagaw, Temesgene Terresa, \\ Solomon Mitiku, Yirgalem Tsehaye, Moges Mokonen, Wakjira Chifra, Habte Nida, \\ Alemu Tirfessa
}

Ethiopian Institute of Agricultural Research (EIAR), Melkassa Agriculture Research Center, Adama, Ethiopia

Email: seyoumamare99@gmail.com

How to cite this paper: Seyoum, A., Semahegn, Z., Nega, A., Siraw, S., Gebreyohannes, A., Solomon, H., Legesse, T., Wagaw, K., Terresa, T., Mitiku, S., Tsehaye, Y., Mokonen, M., Chifra, W., Nida, H. and Tirfessa, A. (2020) Multi-Environment Evaluation and Genotype $\times$ Environment Interaction Analysis of Sorghum [Sorghum bicolor (L.) Moench] Genotypes in Highland Areas of Ethiopia. American Journal of Plant Sciences, 11, 1899-1917.

https://doi.org/10.4236/ajps.2020.1112136

Received: October 8, 2020

Accepted: December 6, 2020

Published: December 9, 2020

Copyright () 2020 by author(s) and Scientific Research Publishing Inc. This work is licensed under the Creative Commons Attribution International License (CC BY 4.0)

http://creativecommons.org/licenses/by/4.0/

(c) (i) Open Access

\begin{abstract}
Sorghum [Sorghum bicolor (L.) Moench] is a high-yielding, nutrient-use efficient, and drought tolerant crop that can be cultivated on over 80 per cent of the world's agricultural land. However, a number of biotic and abiotic factors are limiting grain yield increase. Diseases (leaf and grain) are considered as one of the major biotic factors hindering sorghum productivity in the highland and intermediate altitude sorghum growing areas of Ethiopia. In addition, the yield performance of crop varieties is highly influenced by genotype $x$ environment $(G \times E)$ interaction which is the major focus of researchers while generating improved varieties. In Ethiopia, high yielding and stable varieties that withstand biotic stress in the highland areas are limited. In line with this, the yield performance of 21 sorghum genotypes and one standard check were evaluated across 14 environments with the objectives of estimating magnitude $\mathrm{G} \times \mathrm{E}$ interaction for grain yield and to identify high yielder and stable genotypes across environments. The experiment was laid out using Randomized Complete Block Design with three replications in all environments. The combined analysis of variance across environments revealed highly significant differences among environments, genotypes and $\mathrm{G} \times \mathrm{E}$ interactions of grain yield suggesting further analysis of the $\mathrm{G} \times \mathrm{E}$ interaction. The results of the combined AMMI analysis of variance indicated that the total variation in grain yield was attributed to environments effects $71.21 \%$, genotypes effects $4.52 \%$ and $\mathrm{G} \times \mathrm{E}$ interactions effects $24.27 \%$ indicating the major sources of variation. Genotypes 2006AN7010 and 2006AN7011 were
\end{abstract}


high yielder and they were stable across environments and one variety has been released for commercial production and can be used as parental lines for genetic improvement in the sorghum improvement program. In general, this research study revealed the importance of evaluating sorghum genotypes for their yield and stability across diverse highland areas of Ethiopia before releasing for commercial production.

\section{Keywords}

$\mathrm{G} \times \mathrm{E}$ Interaction, Additive Main Effect and Multiplicative Interaction (AMMI), Genotype and Genotype by Environment (GGE), Genotypes \& Stability

\section{Introduction}

Sorghum [Sorghum bicolor (L.) Moench] is a high-yielding, nutrient-use efficient, and drought tolerant crop that can be cultivated on over 80 per cent of the world's agricultural land. Its geographic distribution spans temperate to tropical climates, and its rich genetic diversity allows for multiple specialized uses. According to [1] sorghum is cultivated in dry lowland, intermediate and highland agro-ecological zones of Ethiopia. Most of the highland agro-ecological sorghum growing areas of the country are characterized by high altitude (more than 1900 masl), high annual rainfall $(\sim 1000 \mathrm{~mm})$ and low temperature.

Globally, sorghum is the fifth most important cereal crop after rice, maize, wheat and barley [2] and its production is estimated to be 62.3 million tons from 42 million hectares of land [3]. Whereas, in Ethiopia it ranks third in area coverage after maize and teff and it has a contribution of $16.4 \%$ of the total annual cereal grain production. Currently sorghum is produced by 6 million holders and its production is estimated to be 5.1 million metric tons from 1.9 million hectares of land giving the national average grain yield of around 2.71 tons per hectare [4]. The crop has multiple uses. Due to food prepared from sorghum is enshrined in the traditional culture of Ethiopia, the grain is preferred for the preparation of various traditional foods like Injera (a leavened bread) and porridge and beverages like Tella and Bordede. Moreover, because of the subsistence nature of sorghum growing farmers in the country, biomass of the crop is important. Hence, biomass of the crop has almost equal importance as grain for animal feed, construction, fuel wood and fencing. To meet these demands, Ethiopia has diverse sorghum germplasm resources that could fulfill the multiple uses of sorghum grower farmers and for the efforts to increase productivity and nutritional quality of sorghum [5].

Despite its importance, the current rate of yield increase and genetic gain in sorghum is inadequate to feed the ever-increasing population [6]. Even though a number of biotic and abiotic stresses are limiting factors for productivity gains, leaf and gain diseases are considered as one of the major biotic factors hindering 
sorghum productivity in the highland and intermediate areas of Ethiopia. In addition, lack of suitable, diseases and striga tolerant and stable varieties across diverse environments is a challenge of sorghum production in the highland and intermediate parts of the country. In order to curve these production constraints and challenges, emphasis has been given by sorghum breeders and pathologists to develop sorghum varieties which are tolerant/resistant to leaf and grain diseases and widely adapted [7]. Hence, developing of tolerant/resistant varieties that can withstand a wide array of stresses through introgression of resistant traits are the strategies which have been implemented in the sorghum breeding in Ethiopia.

Exploitation of genetic variability is the most important tool in plant breeding and this has to be inferred by phenotypic expressions. Phenotype refers to physical appearance or discernible trait of an individual which is dependent on expression of a genotype in environments or the physical or visible characteristics resulting from the interaction between the genetic makeup and the environment. Phenotypes can be observed, measured, classified, or counted. Gene expression is subjected to modification by the environment, therefore genotypic expression of the phenotype is environmentally dependent [8]. The consequences of the phenotypic variation depend largely on the environment. This variation is further complicated by the fact that all genotypes do not react in similar way to change in environment. If relative performance of genotypes is dissimilar in different environments, then Genotype by Environment $(G \times E)$ interaction becomes a major challenge to crop improvement [9]. To reduce $\mathrm{G} \times \mathrm{E}$ interaction problem, trials are usually tested over wide environments to confirm that the selected genotypes have a high and stable performance over diverse range of environments. Varieties with stable yield performance cross arrange of environments is one of the challenges facing plant breeders in generating broadly adapted varieties with superior yield performance [10].

Different statistical models have been used to estimate the $\mathrm{G} \times \mathrm{E}$ interactions component including the classical analysis of variance (ANOVA), various regression models [11] [12], univariate stability analysis [13] [14] and multivariate analysis [15]. Additive Main effect and Multiplicative Interaction (AMMI) model can also be used to quantify stability of the genotypes across locations using the Interaction Principal Component Analysis (IPCAs). [16] stated that the AMMI model proved to be a powerful tool in analyzing $\mathrm{G} \times \mathrm{E}$ interaction patterns. Moreover, the Genotype plus Genotype by Environment Interaction (GGE) biplot model is an important model to analyze multi-environment trial data and to interpret complex $\mathrm{G} \times \mathrm{E}$ interactions (Yan, 2001). It can effectively differentiate and display the interaction pattern graphically and also identifying "which-win-where" and delineation of mega-environments among the testing sites [17]. GGE biplot analysis partitions $\mathrm{G}+\mathrm{G} \times \mathrm{E}$ into principal components through singular value decomposition of environmentally centered yield data [18]. 
In Ethiopia, various researchers have analyzed the nature of $\mathrm{G} \times \mathrm{E}$ interaction effects of sorghum genotypes performance across different sorghum growing agro-ecologies and they reported the existence of high $\mathrm{G} \times \mathrm{E}$ interaction and limited the release of widely adapted sorghum varieties [10] [19] [20] [21] [22].

Many research institutions have been conducting research to identify superior sorghum varieties for better yield performance and wide adaptability for different agro-ecologies of Ethiopia. In line with this, the national and regional sorghum improvement programs have released more than 60 improved sorghum varieties, among these 10 varieties were released for the highland areas of Ethiopia. However, these varieties did not meet the demands of the farmers and thus there is a need to develop varieties that could meet the preference of the farmers.

Hence, the objectives of these experiments were to study the nature and the magnitude of $\mathrm{G} \times \mathrm{E}$ interaction and to identify varieties that are more acceptable for farmers due to higher grain yield and good grain quality while providing much greater stability of performance than currently grown farmer preferred landraces.

\section{Materials and Methods}

\subsection{Description of the Study Area}

The study areas are found in the main highland sorghum growing agro-ecologies of Ethiopia. These locations include Negelle Arsi, Haramaya, Kulumsa, Ambo and Tongo. Evaluation of sorghum genotypes was conducted from 2009 to 2013 in fourteen environments (location-year combinations). The location year-combinations include Negele-Arsi from 2009-2013 (5 environments), Kulumsa from 2009-2013 (5 environments), Ambo 2010 and 2011 (2 environments), Haramaya in 2010 (1 environment) and Tongo in 2013 (1environment) which all trials were conducted in main cropping season. The detailed description, coordinates and agro-ecological features of the testing sites are presented in Table 1.

Table 1. Agro-ecological features of the experimental locations.

\begin{tabular}{cccccccc}
\hline Location & Longitude & Latitude & $\begin{array}{c}\text { Altitude } \\
\text { in m.a.s.l }\end{array}$ & $\begin{array}{c}\text { Soil } \\
\text { type }\end{array}$ & $\begin{array}{c}\text { Annual } \\
\text { average } \\
\text { rainfall } \\
(\mathrm{mm})\end{array}$ & $\begin{array}{c}\text { Annual } \\
\text { average } \\
\text { minimum } \\
\mathrm{T}^{\circ}\left({ }^{\circ} \mathrm{C}\right)\end{array}$ & $\begin{array}{c}\text { Annual } \\
\text { average } \\
\text { maximum } \\
\mathrm{T}^{\circ}\left({ }^{\circ} \mathrm{C}\right)\end{array}$ \\
\hline Negele Arsi & $38^{\circ} 09^{\prime} \mathrm{E}$ & $7^{\circ} 20^{\prime} \mathrm{N}$ & 1947 & Andosol & 915 & 10 & 25 \\
Kulumsa & $39^{\circ} 12^{\prime} \mathrm{E}$ & $07^{\circ} 06^{\prime} \mathrm{N}$ & 2367 & Clay & 840 & 10 & 22 \\
Ambo & $37^{\circ} 51^{\prime} \mathrm{E}$ & $8^{\circ} 59^{\prime} \mathrm{N}$ & 2101 & Verisols & 1018 & 10 & 26 \\
Haramaya & $42^{\circ} 01^{\prime} \mathrm{E}$ & $9^{\circ} 24^{\prime} \mathrm{N}$ & 2047 & $\begin{array}{c}\text { Sandy } \\
\text { clay loam }\end{array}$ & 1260 & 6 & 25 \\
Tongo & $34^{\circ} 21^{\prime} \mathrm{E}$ & $09^{\circ} 23^{\prime} \mathrm{N}$ & 1840 & $\begin{array}{c}\text { Calcaric and } \\
\text { Eutric } \\
\text { Fluvisols }\end{array}$ & & & \\
\hline
\end{tabular}

Source: National metrology datas, m.a.s.l = meters above sea level, $\mathrm{T}^{\circ}=$ Temperature 


\subsection{Planting Materials}

Table 2 presents planting materials and their brief descriptions. The materials for these experiments consisted of twenty-one advanced sorghum genotypes from the pedigree breeding of national sorghum research program based at Melkassa Agricultural Research Center (MARC). These genotypes were generated by crossing and then subsequent selection of the derived segregating generation until they fixed at F6 generation. Subsequent evaluation of the fixed lines has been conducted as preliminary and national variety trials across locations and years. These genotypes were developed for highland sorghum growing areas and we used the standard check Chelenko which was released in 2009 by MARC for highland sorghum growing areas of Ethiopia.

Table 2. Description and pedigrees of sorghum genotypes evaluated at fourteen environments during 2009, 2010, 2011, 2012 and 2013 main cropping season.

\begin{tabular}{|c|c|c|c|}
\hline Entry\# & Genotype Name & Pedigree Name & Background traits \\
\hline 1 & 1999DSBM Progeny \# 3 & 1999DSBM Progeny \# 3 & High lysine \\
\hline 2 & 1999DSBM Progeny \# 47 & 1999DSBM Progeny \# 47 & High lysine \\
\hline 3 & 2000DSBM Progeny \# 15 & 2000DSBM Progeny \# 15 & High lysine \\
\hline 4 & 2005AN6030 & 2005AN6030 & High lysine \\
\hline 5 & 2000DSBM Progeny \# 28 & 2000DSBM Progeny \# 28 & High lysine \\
\hline 6 & 200DSBM Progeny \# 47 & 200DSBM Progeny \# 47 & High lysine \\
\hline 7 & 1998AN DSBM Progeny \# 1 & 1998AN DSBM Progeny \# 1 & High lysine \\
\hline 8 & 1998AN DSBM Progeny \# 10 & 1998AN DSBM Progeny \# 10 & High lysine \\
\hline 9 & 1998AN DSBM Progeny \# 23 & 1998AN DSBM Progeny \# 23 & High lysine \\
\hline 10 & 1998AN DSBM Progeny \# 70 & 1998AN DSBM Progeny \# 70 & High lysine \\
\hline 11 & 2006AN7005 & ETS $639 \times$ P9401 & Striga resistance \\
\hline 12 & 2006AN7010 & ETS $639 \times$ SRN-39 & Striga resistance \\
\hline 13 & 2006AN7011 & ETS $639 \times$ SRN-39 & Striga resistance \\
\hline 14 & 2006AN7013 & ETS $639 \times$ SRN-39 & Striga resistance \\
\hline 15 & 2006AN7017 & ETS $639 \times$ SRN-39 & Striga resistance \\
\hline 16 & 2006AN7019 & ETS $639 \times$ SRN-39 & Striga resistance \\
\hline 17 & 2006AN7022 & ETS $639 \times$ SRN-39 & Striga resistance \\
\hline 18 & 2006AN7026 & ETS $1176 \times 92$ AN5044 & Landrace \\
\hline 19 & ETS-2454 & ETS-2454 & Landrace \\
\hline 20 & 96AN4029 & ACC \# $71076 \times$ Harerge COll \# 4 & Landrace \\
\hline 21 & 96AN4020 & ACC \# $71076 \times$ Harerge COll \# 4 & Landrace \\
\hline 22 & Chelenko (check) & ETS 1176 & Standard check \\
\hline
\end{tabular}

Source: EIAR (Ethiopian Institute of Agricultural Research), Melkassa National Sorghum Research Program. 


\subsection{Experimental Design and Trial Management}

The experiment was laid out using Randomized Complete Block Design (RCBD) replicated three times across all locations and years. Each experimental plot area consisted of 2 rows of $5 \mathrm{~m}$ length with $0.75 \mathrm{~m}$ spacing between rows (inter-row spacing) and $0.20 \mathrm{~m}$ between plants (intra-row spacing). The total area of each plot had a size of $7.5 \mathrm{~m}^{2}$.

As per the recommendation for high land sorghum productions areas of Ethiopia, Diammonium phosphate (DAP) and Urea fertilizers were applied at the rate of $100 \mathrm{~kg} / \mathrm{ha}$ for each fertilizer type. DAP was applied at the time of seed sowing and well-disturbed with the soil to avoid direct contact with the seed and Urea was applied as side dressing after 35 - 40 days of seedling emergence (knee height stage). Thinning was conducted after three weeks of planting to maintain the space between plants and to balance the plant density. Other crop management practices were applied following the recommended practices.

\subsection{Statistical Analysis Methods}

Analysis of variance (ANOVA) was carried out for each environment (location-year combinations) to check whether significance variation was observed among the test genotypes. This was conducted before combined analysis of variance and other multivariate analysis of $\mathrm{G} \times \mathrm{E}$ interaction across the test environments. Furthermore, homogeneity of variance tests (Bartlett's test) was conducted to determine if data from individual environments could be pooled to conduct a combined ANOVA across environments to analyze $\mathrm{G} \times \mathrm{E}$ interactions. The environments were considered as random and genotypes as fixed effects. The sources of variation were put into blocks, treatments and error terms in individual environment analysis of variance. In combined analysis of variance, the treatment effect was further partitioned into three components: $G, E$ and $\mathrm{G} \times \mathrm{E}$ effects. According to [23] the following linear model was fitted for combined ANOVA for this experiment.

$$
y_{i j r}=\mu+\alpha_{i}+\beta_{j}+\alpha \beta_{i j}+b_{j}+\varepsilon_{i j r}
$$

where $y_{i j p}$ is the value of the dependent variable of genotype $i$ in environment $j$ average over block $r, \mu$ is overall mean, $\alpha_{i}$ is the effect of the $i^{\text {th }}$ genotype in the $f^{\text {th }}$ environment, $\beta_{j}$ is the effect of the $f^{\text {th }}$ environment for all genotypes, $\alpha \beta_{i j}$ is the effect of the $i^{\text {th }}$ genotype by the $j^{\text {th }}$ environment, $b_{j}$ is the block effect at the $f^{\text {th }}$ environment and $\varepsilon_{i j r}$ is the residual error term.

The combined ANOVA method sufficiently identified $\mathrm{G} \times \mathrm{E}$ interaction as a significant source of variation but it is not able to explore the nature of $\mathrm{G} \times \mathrm{E}$ interaction which could not show the true performance of genotypes in certain environments [16]. Combined ANOVA determines only if $\mathrm{G} \times \mathrm{E}$ interaction is a significant source of variation or not and estimates it but does not give clear information about the patterns of genotypes or environments that give rise to the interaction [24]. Hence, this calls for to explore further other methods like AMMI and GGE biplot. Thus, the combined data was also analyzed using 
AMMI and GGE model that further divides $\mathrm{G} \times \mathrm{E}$ into IPCA components. Therefore, the AMMI and GGE model analysis had partitioned the $\mathrm{G} \times \mathrm{E}$ into the first two significant IPCAs.

AMMI model was fitted for the grain yield mean data (ton/ha) for each environment (location-year combinations). We used Genstat $17^{\text {th }}$ ed statistical analysis software package to analyze the data. The AMMI model fitted to the data points (Guach, 1992) is:

$$
Y_{i j}=\mu+\alpha_{i}+\beta_{j}+\sum_{n=0}^{N} \lambda_{n} \gamma_{i n} \delta_{j n}+\theta_{i j}+\varepsilon_{i j}
$$

where $Y_{i j}=$ the mean yield of genotype $i$ in environment $j, \mu=$ the grand mean, $\alpha_{i}=$ the deviation of the genotype mean from the grand mean, $\beta_{j}=$ the deviation of the environment mean from the grand mean, $\lambda_{n}=$ the singular value for the IPCA $n, N=$ the number of PCA axis retained in the model, $\gamma_{i n}=$ the PCA score of a genotype for PCA axis $n, \delta_{j n}=$ the environmental PCA score for PCA axis $n$, $\theta_{i j}=$ the Additive Main effects and Multiplicative Interaction residual and $\varepsilon_{i j}=$ the residuals.

$\mathrm{G} \times \mathrm{E}$ interaction analysis was also conducted by GGE biplot which uses singular value decomposition (SVD) to divide genotype plus genotype by environment interaction into two or more principal components. Each principal component consisted of a set of genotype scores multiplied by a set of environment scores to produce a two-dimensional biplot [25]. In GGE interaction biplots were considered together and to accomplish this $\mathrm{G}+\mathrm{GE}$ effects are separated out from the observed mean and eventually the model becomes as $Y-\mu-\beta=\alpha+\alpha \beta$. The genotype plus $\mathrm{G} \times \mathrm{E}$ interaction effect was divided into multiplicative terms using SVD. The model was computed based on singular value decomposition (SVD) of first two principal components as:

$$
Y_{i j}-\mu \beta_{j}=\lambda_{i} \xi_{i 1} \eta_{1 j}+\lambda_{2} \xi_{i 2} \eta_{2 i}+\xi_{i j}
$$

where $\lambda_{1}$ and $\lambda_{2}$ are the singular values of the first and second highest principal components, PC1 and PC2, respectively; $\xi_{1}$ and $\xi_{2}$ are the eigenvectors of genotype I for PC1 and PC2, respectively, and $\eta_{1}$ and $\eta_{2}$ are the eigenvectors of environment $\mathrm{j}$ for $\mathrm{PC} 1$ and $\mathrm{PC} 2$, respectively.

\section{Results and Discussion}

Data were collected on twenty-one (21) sorghum genotypes developed through pedigree breeding via Ethiopian institute of agricultural research, Melkassa $\mathrm{Na}$ tional sorghum research program along with recently released standard check variety were subjected to analysis of variance (ANOVA) in order to assess the presence of genetic variability among elite sorghum genotypes and the results are presented in tables and figures below.

\subsection{Mean Performance of Test Genotypes}

Table 3 shows the mean grain yield performance of 22 test genotypes including 
Table 3. A matrix of genotypes mean response evaluated across 14 environments and the environments mean across 22 genotypes.

\begin{tabular}{|c|c|c|c|c|c|c|c|c|c|c|c|c|c|c|c|}
\hline \multirow{2}{*}{ Entry\# } & \multicolumn{14}{|c|}{ Environments } & \multirow{2}{*}{$\begin{array}{c}\text { Genotype } \\
\text { Mean }\end{array}$} \\
\hline & 09AN & $09 \mathrm{KU}$ & $10 \mathrm{AB}$ & $10 \mathrm{AN}$ & $10 \mathrm{HU}$ & $10 \mathrm{KU}$ & $11 \mathrm{AB}$ & $11 \mathrm{AN}$ & $11 \mathrm{KU}$ & $12 \mathrm{AN}$ & $12 \mathrm{KU}$ & $13 \mathrm{AN}$ & $13 \mathrm{KU}$ & $13 \mathrm{TG}$ & \\
\hline 1 & 5037 & 1541 & 972 & 2408 & 5807 & 1333 & 2535 & 3293 & 2904 & 6084 & 811 & 3035 & 3417 & 2643 & 2987.1 \\
\hline 2 & 6044 & 1245 & 793 & 2570 & 4066 & 2133 & 3621 & 4948 & 2905 & 4579 & 1803 & 4869 & 2518 & 2421 & 3179.6 \\
\hline 3 & 4354 & 1363 & 1392 & 2385 & 1837 & 1452 & 3467 & 3763 & 2430 & 4083 & 427 & 4652 & 2811 & 1996 & 2600.9 \\
\hline 4 & 3556 & 1282 & 624 & 2763 & 2211 & 2074 & 3524 & 4059 & 1674 & 5255 & 927 & 3704 & 2469 & 1171 & 2520.9 \\
\hline 5 & 7111 & 1370 & 1328 & 2607 & 3577 & 1630 & 3043 & 4355 & 2926 & 4248 & 1446 & 4372 & 2696 & 1384 & 3006.6 \\
\hline 6 & 5156 & 830 & 812 & 3320 & 6133 & 2726 & 3672 & 4266 & 3052 & 4320 & 1751 & 3645 & 4326 & 1359 & 3240.6 \\
\hline 7 & 5393 & 933 & 715 & 5272 & 4963 & 2667 & 2666 & 4001 & 3259 & 4406 & 788 & 4290 & 3467 & 1446 & 3161.9 \\
\hline 8 & 4763 & 718 & 745 & 2074 & 7253 & 1837 & 1949 & 3526 & 2415 & 7299 & 916 & 2519 & 2193 & 852 & 2789.9 \\
\hline 9 & 4059 & 571 & 890 & 3035 & 4667 & 2252 & 2443 & 3082 & 1392 & 6934 & 1480 & 3971 & 2193 & 2635 & 2952.1 \\
\hline 10 & 4978 & 1215 & 656 & 3694 & 3615 & 2815 & 3239 & 3607 & 3081 & 4622 & 1751 & 4342 & 2193 & 1639 & 3086.8 \\
\hline 11 & 6244 & 1446 & 565 & 2452 & 4252 & 1955 & 2983 & 4334 & 2333 & 5423 & 1274 & 3618 & 2193 & 447 & 2936.6 \\
\hline 12 & 6133 & 1511 & 1269 & 3178 & 4800 & 2385 & 2995 & 3763 & 4023 & 4681 & 704 & 7013 & 2193 & 4742 & 3517.2 \\
\hline 13 & 6987 & 1978 & 193 & 2607 & 4050 & 2844 & 4313 & 3940 & 4519 & 4237 & 941 & 3862 & 2193 & 3712 & 3409.9 \\
\hline 14 & 6963 & 1200 & 919 & 3230 & 3890 & 1926 & 3228 & 3170 & 1600 & 4444 & 1140 & 4622 & 2193 & 3365 & 3058.9 \\
\hline 15 & 3502 & 326 & 427 & 2719 & 2785 & 1392 & 3178 & 3289 & 711 & 4741 & 545 & 2940 & 2193 & 2254 & 2170.0 \\
\hline 16 & 5511 & 1933 & 586 & 4178 & 2685 & 2133 & 3640 & 4000 & 3127 & 4487 & 1503 & 3019 & 2193 & 1900 & 2988.8 \\
\hline 17 & 7718 & 2222 & 706 & 2261 & 2978 & 3259 & 3423 & 4534 & 3793 & 4413 & 546 & 3595 & 2193 & 4678 & 3391.0 \\
\hline 18 & 5615 & 503 & 362 & 2696 & 4119 & 1512 & 2933 & 4889 & 1956 & 4355 & 1043 & 2951 & 2193 & 1991 & 2712.6 \\
\hline 19 & 4215 & 2311 & 685 & 2506 & 3578 & 2696 & 4189 & 4030 & 5126 & 5659 & 3231 & 3303 & 2193 & 1132 & 3237.9 \\
\hline 20 & 6045 & 2074 & 1418 & 3704 & 5185 & 2652 & 3493 & 3052 & 3719 & 4516 & 2704 & 3792 & 2193 & 2760 & 3482.7 \\
\hline 21 & 5869 & 2371 & 235 & 2548 & 4711 & 2726 & 3407 & 4503 & 4385 & 5544 & 1586 & 3799 & 2193 & 3638 & 3511.2 \\
\hline 22 & 5334 & 466 & 907 & 2667 & 4474 & 2607 & 3765 & 3852 & 2785 & 4297 & 2290 & 6835 & 2193 & 1854 & 3233.9 \\
\hline Envi. Mean & 5481 & 1337 & 782 & 2949 & 4165 & 2228 & 3259 & 3921 & 2914 & 4938 & 1346 & 4034 & 2193 & 2274 & 3053.5 \\
\hline LSD (5\%) & 279 & 169.1 & 87.91 & 261.3 & 431.9 & 265.7 & 314.7 & 301.1 & 297.5 & 403.5 & 156.6 & 376.5 & 2193 & 223.2 & 278.2 \\
\hline CV (5\%) & 8.37 & 20.78 & 18.48 & 14.56 & 17.04 & 19.6 & 15.87 & 12.62 & 16.77 & 13.43 & 19.13 & 15.34 & 2193 & 16.13 & 16.1 \\
\hline
\end{tabular}

one standard check (Chelenko) across the highland representative testing sites (Negele Arsi, Kulumsa, Haramaya, Ambo and Tongo) for the period of 2009-2013. The overall mean grain performance of all genotypes across all 14 environments was $3053.5 \mathrm{~kg} / \mathrm{ha}$ with a range 2170.0 to $3517.5 \mathrm{~kg} / \mathrm{ha}$. Comparing the test genotypes with the standard check variety Chelenko, seven genotypes had performed better than the check with a grain yield advantage which ranged from $5.7 \%$ to $14.3 \%$ (Table 4 ). The genotype with a code 2006AN7010 gave the highest mean grain yield $(3517.2 \mathrm{~kg} / \mathrm{ha})$ performance across all the test environments. Furthermore, this genotype 2006AN7010 and another genotype 2006AN7011 showed a yield advantage of $14.3 \%$ and $11.0 \%$ respectively over the 
Table 4. Combined ANOVA for grain yield ( $\mathrm{kg} / \mathrm{ha}$ ) of twenty-two sorghum genotypes evaluated across fourteen environments from 2009-2013 main cropping season.

\begin{tabular}{cccc}
\hline Sources of variation & DF & \multicolumn{1}{c}{ SS } & MS \\
\hline Genotype & 21 & $103,723,452$ & $4,939,212^{* *}$ \\
Environment & 13 & $1,635,842,871$ & $125,834,067^{\star *}$ \\
G $\times$ E & 273 & $557,578,203$ & $2,042,411^{* *}$ \\
Replicate/Environment & 28 & $9,885,064$ & $353,038^{*}$ \\
Error & 588 & $136,516,548$ & 232,171 \\
Total & 923 & $2,443,545,585$ & $2,647,395$ \\
\hline
\end{tabular}

check. These genotypes also showed good head exertion, grain color and compactness over the standard check Chelenko (data not shown) which all are a trait preferred by sorghum growing farmers.

Regarding the environment response, the highest mean grain yield performance was obtained at Negelle Arsi in 2009 and 2012 with $7718.0 \mathrm{~kg} / \mathrm{ha}$ and $7299.0 \mathrm{~kg} / \mathrm{ha}$ respectively. But the lowest mean grain yield $(235.0 \mathrm{~kg} / \mathrm{ha})$ was recorded in 2010 at Ambo. There is a rank change of genotypes from environment to environment. This change of ranks of genotypes indicated the presence of cross over interaction across environments. In general, the change in genotype performance from one environment to another environment dictates the presence of $\mathrm{G} \times \mathrm{E}$ interaction and needs further investigation to know the patterns of interactions. This is due to the seasonal variability which could influence the variation in genetic response of the test genotypes.

\subsection{Combined Analysis of Variance}

Prior to conducting combined analysis of variance, each individual environment analysis of variance was computed and all environments showed significant variation (data not showed here) among the test genotypes which called for combined analysis of variance. Moreover, homogeneity of error variance was determined by Bartlett's test and the error variances of each individual environment were found homogenous. Besides, normality test was also performed using Chi-square test and the data were derived from normal distribution.

The combined analysis of variance partitioned the sources of variation into components for grain yield of twenty-two sorghum genotypes evaluated in 14 environments which is presented in Table 5. The results showed that there were highly significant $(\mathrm{p} \leq 0.001)$ differences among genotypes, environments and $\mathrm{G}$ $\times$ E interaction (Table 4). The proportion of the variability accounted for by the environment, genotype and $\mathrm{G} \times \mathrm{E}$ interaction contribution of each source of variation varies enormously with the largest sources of variation is attributed to environment (66.95\%) followed by $\mathrm{G} \times \mathrm{E}(22.82 \%)$. However, genotype sources of variation contributed the least (4.24\%) and the residual is about (5.59\%). Large proportions of variability explained by environmental effects obviously 
Table 5. AMMI G $\times \mathrm{E}$ interaction analysis of variance of grain yield $(\mathrm{kg} / \mathrm{ha})$ of sorghum genotypes evaluated in fourteen environments from 2009-2013 main cropping season in Ethiopia.

\begin{tabular}{cccccccc}
\hline Source & DF & SS & MS & $\begin{array}{c}\% \\
\text { Total }\end{array}$ & $\begin{array}{c}\% \\
\text { Treatment }\end{array}$ & $\begin{array}{c}\% \\
\text { G } \times \mathrm{E}\end{array}$ & $\begin{array}{c}\% \\
\text { Cumulative }\end{array}$ \\
\hline Total & 923 & $2,443,546,003$ & $2,647,395$ & & & & \\
Treatments & 307 & $2,297,144,387$ & $7,482,555$ & 94.01 & & & \\
Genotypes & 21 & $103,723,442$ & $4,939,212$ & & 4.52 & & \\
Environments & 13 & $1,635,842,867$ & $125,834,067$ & 71.21 & & \\
Block & 28 & $9,885,063$ & 353,038 & & & & \\
Interactions & 273 & $557,578,079$ & $2,042,411$ & & 24.27 & & \\
IPCA 1 & 33 & $161,243,307$ & $4,886,161$ & & & 28.92 & 28.92 \\
IPCA 2 & 31 & $93,504,974$ & $3,016,289$ & & & 16.77 & 45.69 \\
Residuals & 209 & $302,829,797$ & $1,448,946$ & & & 54.31 & 100 \\
Pooled error & 588 & $136,516,552$ & 232,171 & 5.59 & & & \\
\hline
\end{tabular}

indicate that the larger contribution of the environmental effects on the sorghum performance. The significant effect of environments was due to their variation in rainfall amount and seasonal distribution, temperature and soil type. This indicated that the environments contribution for performance of genotypes accounted for larger proportion. The larger proportion of environmental variation dictates that genotypes need to be tested for their specific adaptation and commercial release. In addition, the presence of highly significant $\mathrm{G} \times \mathrm{E}$ component of variance showed that the performance of the genotypes differs across each target environments. Similarly, there was a greater grain yield variation among test genotypes across environments due to inherent genetic variation of genotypes coupled with variation in amount, pattern and distribution of rainfall. Moreover, the environmental variation is due to soil and year to year climate variation. In line with this, [20] [21] [22] reported that significant variation observed among the performance of genotypes, environment and $\mathrm{G} \times \mathrm{E}$ interaction effects for the low land adapted sorghum genotypes. Since the combined analysis of variance only depicts whether the $\mathrm{G} \times \mathrm{E}$ interaction component is significant or not, further analysis to identify the stable and widely adapted genotypes is required. In this case, we analyzed the data using AMMI and GGE biplot.

\section{Stability Analysis}

\subsection{Analysis}

Table 5 shows the combined AMMI model ANOVA of the twenty-two genotypes across fourteen environments for grain yield ( $\mathrm{kg} / \mathrm{ha})$. The ANOVA revealed highly significant variation $(p<0.001)$ for the environments, genotypes and $\mathrm{G} \times \mathrm{E}$ components. The total percentage of variation which has been explained by the model was $94.01 \%$ for treatments and $5.59 \%$ for error. The greater 
contribution of the treatments than the error indicates the reliability of this multi-environment experiment (Table 5). The variation which was accounted for by environments, genotype and $\mathrm{G} \times \mathrm{E}$ was $71.21 \%, 4.52 \%$ and $24.27 \%$, respectively. As stated earlier, the high percentage of the environmental variation is an indication that the major factor that affects grain yield performance of sorghum in highland areas of Ethiopia is the environmental effect. Similar results have been reported for different sorghum genotypes evaluated in various environments [10] [20] [21] [22] [26] [27]. In the AMMI ANOVA, the $\mathrm{G} \times \mathrm{E}$ source of variation was further partitioned by IPCA. The Gollob F-test was used to estimate significance of the $\mathrm{G} \times \mathrm{E}$ components. The number of IPCA axis to be retained is identified by testing the mean square of each axis with the estimate of error through the F-statistic. The result of the test revealed that the first two IPCA are significant at 0.001 probability level, suggesting retaining of only the first two interactions IPCA axes in the model. Therefore, the best fit AMMI model for this multi-environment yield trial data was AMMI-2.

The interaction principal component 1 (IPCA1) plotted in the $\mathrm{x}$-axis and the interaction principal component 2 (IPCA2) plotted in the y axis revealed that the first IPCA captured $28.92 \%$ of the total interaction sum of squares, while the second IPCA explained $16.77 \%$ of the interaction sum of squares. [18] also recommended that the most accurate model for AMMI can be predicted by using the first two IPCAs. In the current study the first two IPCAs accounted for a total of $45.69 \%$ of the interaction with 64 the corresponding degrees of freedom. This shows that the $\mathrm{G} \times \mathrm{E}$ interaction of the twenty-two sorghum genotypes with fourteen environments could be adequately predicted by the first two principal components axes and therefore, possible to graphically display in AMMI1 and AMMI2 biplot.

The AMMI1 biplot displays the means of the main effects of grain yield on the abscissa and IPCA1 values as the ordinates. Hence, genotypes or environments that laid on a vertical line have similar means and those that laid on a horizontal line have similar interaction patterns [16]. The biplot in Figure 1 shows seven of the fourteen environments (Ambo 2010, Kulumsa 2012, Kulumsa 2009, Kulumsa 2010, Tongo 2013, Kulumsa 2011 and Negele-Arsi 2010) below average performance and unsuitable to the performance of some of the total genotypes compared to the rest seven environments. The remaining seven environments i.e., Negele-Arsi 2009 and Negele-Arsi 2013, Ambo 2011, Kulumsa 2013, Negele-Arsi 2012, Haramaya University 2010 and Negele-Arsi 2011 have the highest responses and are favorable to the performance of almost all of the genotypes. Similar results for other genotypes in different agro-ecologies have been reported by [20] [21] [22] [28]. AMMI-2 biplot displays the pattern of the first two IPCAs of the interaction effects and helps for visual interpretation of the $\mathrm{G} \times \mathrm{E}$ interaction patterns and determine genotypes or environments that reveal small and large interaction effects. Moreover, in AMMI-2 biplot, environments fall into three sections based on the length of spoke (Figure 2). Among the environments $\mathrm{Ne}$ gele-Arsi 2010, Negele-Arsi 2011, Kulumsa 2009, Kulumsa 2010, Kulumsa 2011, 


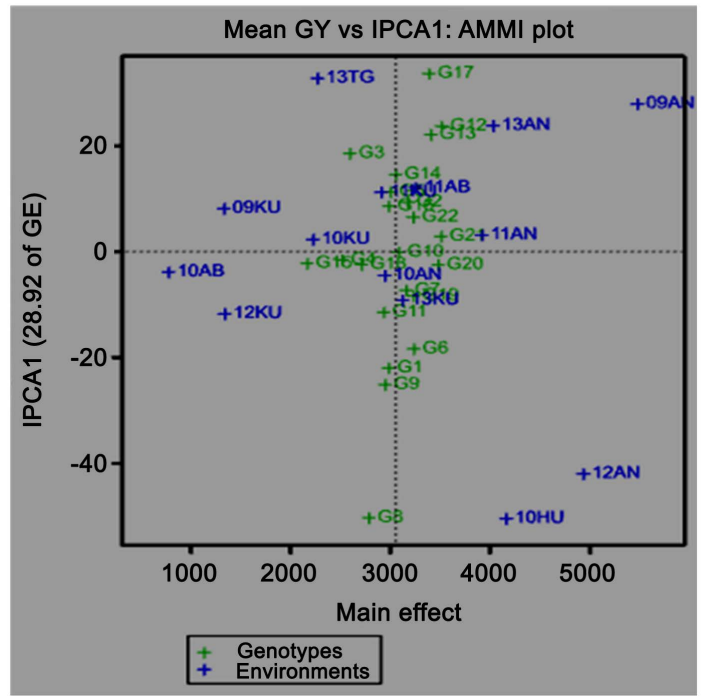

Figure 1. AMMI 1 biplot showing the grain yield performance of sorghum genotypes evaluated across fourteen environments.

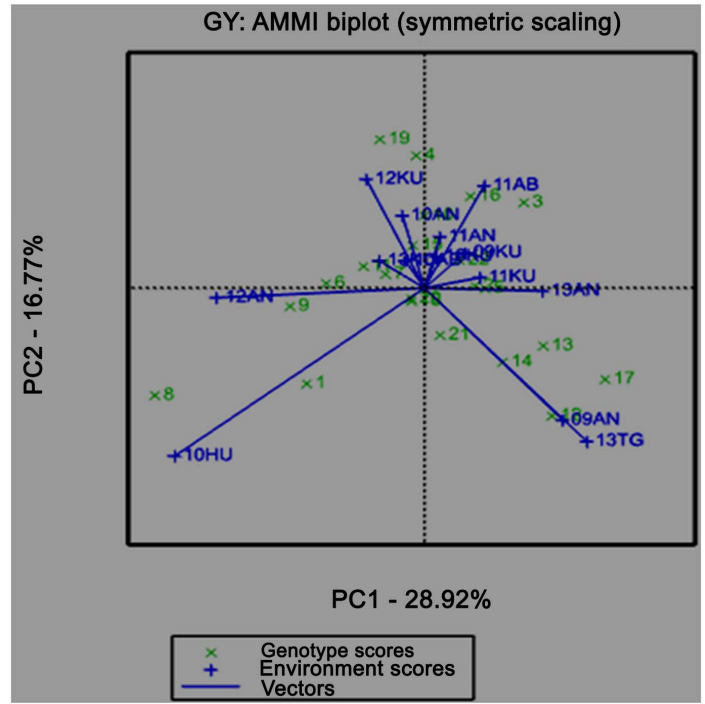

Figure 2. AMMI 2 biplot showing IPCA1 vs IPCA2 for grain yield (kg/ha) of sorghum genotypes evaluated in fourteen environments.

Kulumsa 2013 and Ambo 2010 have very short spoke whereas Kulumsa 2012, Ambo 2011, Negele-Arsi 2012 and 2013 have short spokes. They do not exert strong interaction but the environments Haramaya University 2010, Negele-Arsi 2009 and Tongo 2013 have long spokes and hence show the most discriminating environments. In a similar fashion, in AMMI-2 biplot the genotypes G19, G8, G17, G13, G3 and G12 are the best or poorest genotypes in some or all environments because they are farthest from the origin where as the best genotype is G12 with respect to the best enhancing environment Negele-Arsi 2013 and the poor genotype is $\mathrm{G} 3$ due to its value below average value.

On the other hand, the genotypes, G6, G2, G7, G22, G20, G5, G15, G11, G18, and G21 were close to the origin and therefore were less/non-sensitive to envi- 
ronmental interaction. However, genotype G15, G5, G11 and G18 were low yielding due to below average grain yield (Figure 2). Similar findings were stated by [16] [20] [21] [22] [29].

\subsection{GGE Biplot Analysis}

Stability analysis of the genotypes based on their IPCA scores using the GGE biplot analysis is shown in Figure 3 and Figure 4. The polygon of lines in Figure 3 is made by connecting vertex genotypes, by connecting straight lines and rest of genotypes fall inside the polygon. The vertex genotypes were G8, G20, G17, G3 and G15 (Figure 3). These genotypes are either the best or poorest genotypes in some or all environments because they are farthest from the origin.

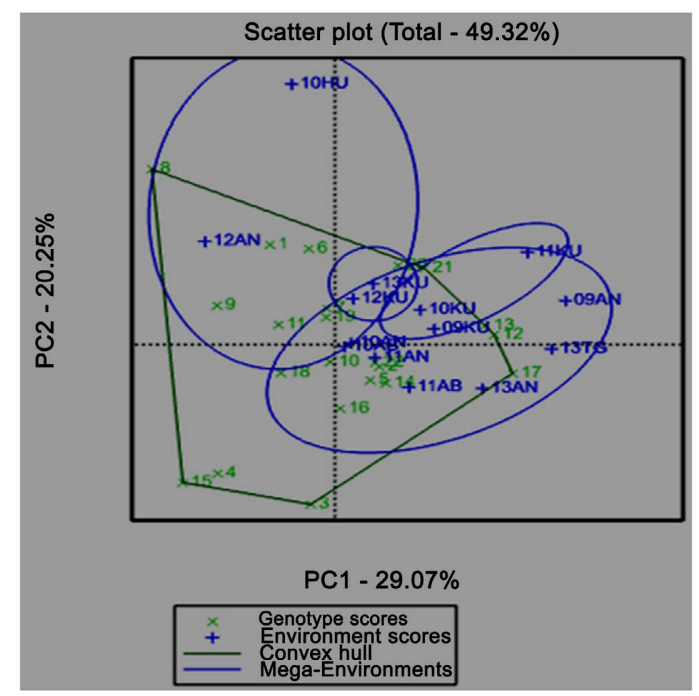

Figure 3. The which-won-where view of the GGE biplot to show which sorghum genotypes performed best in which environments (mega-environment identification).

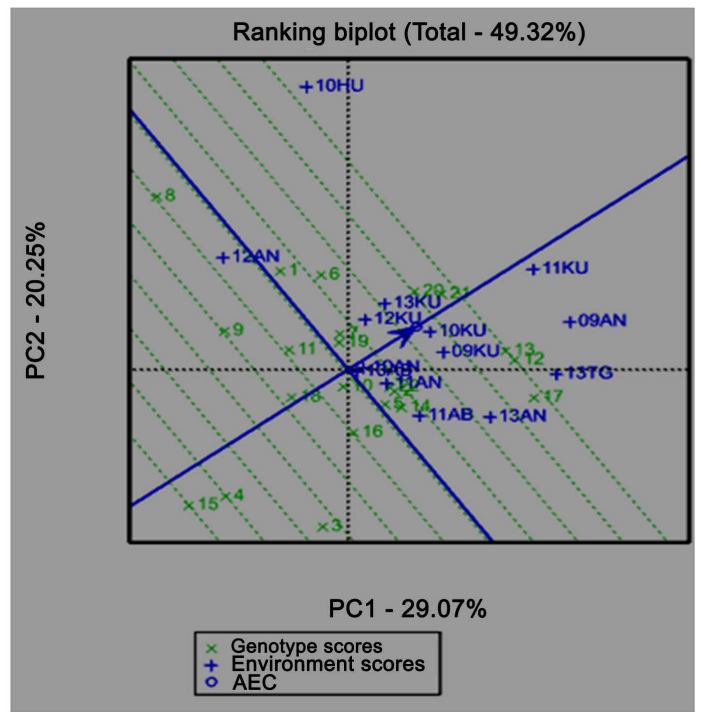

Figure 4. GGE ranking biplot indicates the mean grain yield and stability performance of 22 evaluated sorghum genotypes. 
In the current study, the GGE biplot analysis of the twenty-two sorghum genotypes tested at fourteen environments showed that the first two principal components explained $49.32 \%$ of the total variance (Figure 3). Genotypes close to the origin are not sensitive to the environments and those distant from the origin are sensitive to environments and have large interactions. Accordingly, statistically stable genotypes and locations were situated close to the biplot origin, with scores practically zero for the two-interaction axis (IPCA1 and IPCA2). Determining of mega-environments (Figure 3 ) was also studied and information on which-won-where was also shown in the graph generated. The mega-environment identification contained a condition whereby one or more environments with similar characteristics were partitioned into one large environment. [17] [18] [25] explained mega-environments as a group of locations or environments that constantly share the same best variety. This permits the researcher to have specific and valid explanation to recommend the candidate genotypes which are good for that specific environment [30].

Which-won-where determined best winner genotypes for the mega-environment. This also means the genotypes can be evaluated in those few mega-environments and still good yield data results can be found. The first mega environment contained environments of HU 2010, Negele-Arsi 2012 with winning genotype 6, were grouped into one environment, the second Mega-environment contained Negele-Arsi 2009, Tongo 2013, Negele-Arsi 2013, Ambo 2011, Negele-Arsi 2010, Negele-Arsi 2011 with winning genotype 12 , the third mega-environment contained Kulumsa 2010, Kulumsa 2009, Kulumsa 2011 with winning genotype 21, and on the other hand the fourth mega-environment contained only two environments of $\mathrm{Ku}$ lumsa 2012 and Kulumsa 2013 with winning genotype 20 meaning in the future, costs of multi-environment trials will be reduced by placing that effect into account (Gupta et al., 2013). The GGE have much information which validates conducive environment for testing and favorable genotypes for identification and recommendation, there was effective testing of environments and genotypes based on the mean performance and stability across environments which is valuable required information for a crop breeder.

\subsection{Mean Performance and Stability of Genotypes Using GGE Biplot}

The average environment coordinate (AEC) view of the GGE biplot: The average tester coordinate (ATC) group genotypes with above average mean from below average means. Therefore, genotypes with above average means were 14, 10, 7, 2, $22,19,6,17,13,20,21$ and 12 while $15,4,3,18,8,11,9,1,16$ and 5 were genotypes which had below average mean performance (Figure 4 ). The shorter the genotype vector is, the more stable it is than others. Hence, among tested genotypes 13 and 12 were identified as high yielder and stable genotype. Similar findings were reported by [19] [20] [21] [22].

Comparison biplot of fourteen test environments: The average environments 
coordinate (AEC) is a line that pass through the average environment (represented by small circle) and biplot origin. A test environment that has a small angle with the AEC is more representative of other test environments. Therefore, Kulumsa 2011 was more representative testing environment (Figure $5)$. An ideal genotype should have high mean grain yield performance across environments (Figure 6). It is the one which is close or at the center of the concentric circle, and is also a genotype to be on average environmental coordinate (AEC) on positive direction and has vector length equal to the longest vector of the genotype and designated by an arrow pointed to it [17] [31]. The biplot showed that genotype 21 is the most ideal genotype.

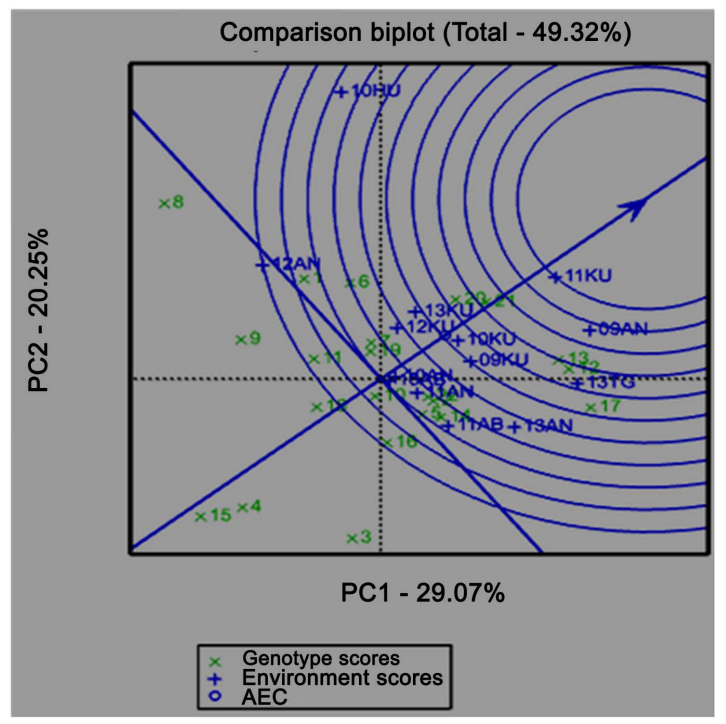

Figure 5. GGE-biplot showing a comparison of 14 testing environments with in ideal environment for grain yield ( $\mathrm{kg} / \mathrm{ha})$.

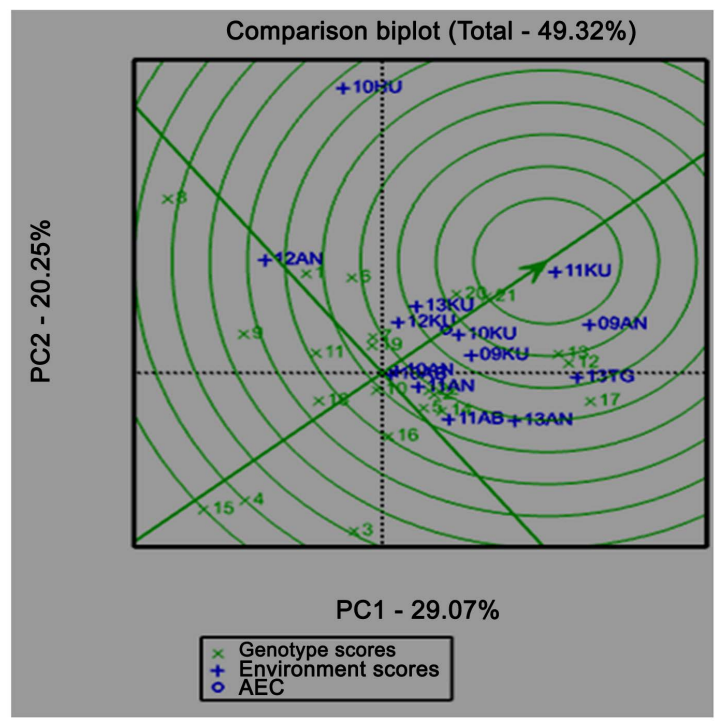

Figure 6. GGE-biplot showing a comparison of all genotypes with in good performing ideal genotypes for grain yield (kg/ha). 


\section{Conclusions}

Sorghum is a high-yielding, nutrient-use efficient, and drought tolerant crop that can be cultivated on over 80 per cent of the world's agricultural land. Its geographic distribution spans temperate to tropical climates, and its rich genetic diversity allows for multiple specialized uses including grain, forage and an increasing number of food applications.

These experiments were executed to study the nature and the magnitude of $G$ $\times \mathrm{E}$ interaction and identify and release varieties that are more acceptable for farmers due to higher grain yield and good grain quality while providing much greater stability of performance than currently grown farmer preferred landraces. The field experiment was conducted using Randomized Complete Block Design (RCBD) in row column arrangement replicated three times across all locations and years. Twenty-two sorghum genotypes along with standard check were evaluated in fourteen high land environments. Various statistical models were used to model the $\mathrm{G} \times \mathrm{E}$ interaction sources of variation in highland testing environments. Combined analysis of variance showed highly significant variation for genotypes, environments and $\mathrm{G} \times \mathrm{E}$ interaction suggesting further analysis of the $\mathrm{G} \times \mathrm{E}$ interaction sources of variation. The AMMI analysis for the additive main effect and multiplicative interaction effect showed significant difference for genotype, environment and genotype by environment interaction. The first interaction principal component (IPCA 1) contributed major part of the interaction $28.92 \%$ and the second interaction principal component explained additional $16.77 \%$ and both together explained $45.69 \%$ of the genotype by environment interaction. Additive Main effects and Multiplicative Interaction and Genotype Plus Genotype by Environment Interaction (GGE) biplot were used to determine high yielder and stable genotypes across environments. Genotype 2006AN7010 and 2006AN7011 were high yielder and stability, and therefore, are the promising ones, while the low yielder and stable genotype was genotype 2006AN7017 across the test environments. In summary, One (1) variety that is more acceptable for farmers due to higher grain yield and good grain quality while providing much greater stability of performance than currently grown farmer preferred varieties and landraces has been identified and released for commercial production

\section{Acknowledgements}

Thanks to Ethiopian Institutes of Agricultural Research (EIAR), Bill and Melinda gate foundation and National Sorghum research program researchers and technicians for their assistance in developing the breeding pipelines and field evaluation.

\section{Conflicts of Interest}

The authors declare that no conflicts of interest regarding the publication of this manuscript. 


\section{References}

[1] Gorfu, D. and Ahmed, E. (2011) Crops and Agro Ecological Zones in Ethiopia. RN TIGRAY 2, April 2009.

[2] FAOSTAT (2019) Food and Agriculture Organization of the United Nations STAT. http://www.fao.org/faostat/en/\#data/QC

[3] USDA (2017) World Agricultural Production U.S. Department of Agriculture Foreign Agricultural Service/Office of Global Analysis International Production Assessment Division (IPAD), Washington DC, 20250-21051.

[4] Central Statistical Agency of Ethiopia (2018) Agricultural Sample Survey 2017/2018.

[5] Amsalu, A., Bryngelsson, T. and Bekele, E. (2000) Genetic Variation of Ethiopian and Eritrean Sorghum (Sorghum bicolor (L.) Moench) Germplasm Assessed by Random Amplified Polymorphic DNA (RAPD). Genetic Resources and Crop Evolution, 47, 471-482.

[6] Tsegaye, G., Taye, T., Amare, S. and Hussein, M. (2020) Genetic Progresses from over Four Decades of Sorghum [Sorghum bicolor (L.) Moench, Poaceaea Family] Breeding in Ethiopia. African Journal of Biotechnology, 19, 710-735. https://doi.org/10.5897/AJB2019.16932

[7] Gebreyohannes, A., Tadesse, T., Seyoum, A., Nida, H., Nega, A., Senbetay, T. and Endalemaw, C. (2018) Genetic Variability in Agronomic Traits and Associations in Sorghum [(Sorghum bicolor (L.) Moench)] Genotypes at Intermediate Agro-Ecology Sorghum Growing Areas of Ethiopia. African Journal of Agricultural Research, 13, 2780-2787. https://doi.org/10.5897/AJAR2018.13481

[8] Kang, M. (1998) Using Genotype-by-Environment Interaction for Crop Cultivar Development. Advances in Agronomy, 62, 199-252.

https://doi.org/10.1016/S0065-2113(08)60569-6

[9] Allard, R.W. (1960) Principles of Plant Breeding. John Willey and Sons, New York, $485 \mathrm{p}$.

[10] Adugnua, A. (2007) Assessment of Yield Stability in Sorghum. African Crop Science Journal, 15, 83-92. https://doi.org/10.4314/acsj.v15i2.54421

[11] Eberhart, S. and Russell, W. (1966) Stability Parameters for Comparing Varieties. Crop Science, 6, 36-40.

https://doi.org/10.2135/cropsci1966.0011183X000600010011x

[12] Finlay, K. and Wilkinson, G. (1963) The Analysis of Adaptation in a Plant Breeding Program. Australian Journal of Agricultural Research, 14, 742-754. https://doi.org/10.1071/AR9630742

[13] Shukla, G. (1972) Some Statistical Aspects of Partitioning Genotype-Environmental Components of Variability. Heredity, 29, 237-245. https://doi.org/10.1038/hdy.1972.87

[14] Lin, C., Binns, M. and Lefkovitch, L. (1986) Stability Analysis: Where Do We Stand? Crop Science, 26, 894-900. https://doi.org/10.2135/cropsci1986.0011183X002600050012x

[15] Gauch, H.G. and Zobel, R.W. (1997) Identifying Mega-Environments and Targeting Genotypes. Crop Science, 37, 311-326. https://doi.org/10.2135/cropsci1997.0011183X003700020002x

[16] Crossa, J., Gauch, H.G. and Zobel, R.W. (1990) Additive Main Effects and Multiplicative Interaction Analysis of Two International Maize Cultivar Trials. Crop Science, 30, 493-500. https://doi.org/10.2135/cropsci1990.0011183X003000030003x

[17] Yan, W. and Tinker, N.A. (2006) Biplot Analysis of Multi-Environment Trial Data: 
Principles and Applications. Canadian Journal of Plant Science, 86, 623-645. https://doi.org/10.4141/P05-169

[18] Yan, W. (2001) GGE Biplot: A Windows Application for Graphical Analysis of Multienvironment Trial Data and Other Types of Two-Way Data. Agronomy Journal, 93, 1111-1118. https://doi.org/10.2134/agronj2001.9351111x

[19] Nida, H., Seyoum, A. and Gebreyohannes, A. (2016) Evaluation of Yield Performance of Intermediate Altitude Sorghum (Sorghum bicolor (L.) Moench) Genotypes Using Genotype $\times$ Environment Interaction Analysis and GGE Biplot in Ethiopia. International Journal of Trend in Research and Development, 3, 27-35.

[20] Amare, S., Adane, G., Amare, N., Habte, N., Taye, T., Alemu, T. and Tamirat, B. (2019) Performance Evaluation of Sorghum (Sorghum bicolor (L.) Moench) Genotypes for Grain Yield and Yield Related Traits in Drought Prone Areas of Ethiopia. Advances in Crop Science and Technology, 7, 439.

[21] Amare, S., Amare, N., Kedanemaryam, W., Taye, T., Diriba, T., Alemu, T., Habte, N., Adane, G., Sewmehone, S., Tsegaye, G., Chalachew, E., Hailemariam, S., Tamirat, B., Tokuma, L., David, J., Emma, M., Daniel, N., Ligaba, A. and Meron, B. (2020) Multi Environment and Spatial Analysis of Early Maturing Sorghum [Sorghum bicolor (L.) Moench] Genotypes in Dry Lowland Areas of Ethiopia. African Journal of Agricultural Research, 15, 278-290. https://doi.org/10.5897/AJAR2019.14495

[22] Yitayeh, Z.S., Bisetegn, K.B., Mindaye, T.T. and Bisetegn, K.B. (2019) AMMI and GGE Analysis of $\mathrm{G} \times \mathrm{E}$ and Yield Stability of Early Maturing Sorghum [Sorghum bicolor (L.) Moench] Genotypes in Dry Lowland Areas of Ethiopia. Advances in Crop Science and Technology, 5, 425.

[23] Ding, M., Tier, B. and Yan, W. (2007) Application of GGE Biplot Analysis to Evaluate Genotype, Environment and $\mathrm{G} \times \mathrm{E}$ Interaction on $P$. radiata: A Case Study. http://proceedings.com.au/afgc/slides\%20(PDF)/thurs\%201600\%20ding.pdf

[24] Samonte, S.O.P., Wilson, L.T., McClung, A.M. and Medley, J.C. (2005) Targeting Cultivars onto Rice Growing Environments Using AMMI and SREG GGE Biplot Analyses. Crop Science, 45, 2414-2424. https://doi.org/10.2135/cropsci2004.0627

[25] Yan, W. and Wu, H.X. (2008) Application of GGE Biplot Analysis to Evaluate Genotype (G), Environment (E), and $\mathrm{G} \times \mathrm{E}$ Interaction on Pinus radiata: A Case Study. New Zealand Journal of Forestry Science, 38, 132-142.

[26] Abiy, L. and Firew, M. (2016) Genotype $\times$ Environment Interaction and Stability of Early Maturing Sorghum [Sorghum bicolor (L.) Moench] Genotypes in Ethiopia. M.Sc. Thesis, Haramaya University of Agriculture, Haramaya.

[27] Kinde, L., Gebeyehu, C., Abubeker, T., Dadi, G., Shanene, H., et al. (2016) Evaluation of Sorghum (Sorghum bicolor (L) Moench) Varieties and Environments for Yield Performance and Stability. Journal of Biology, Agriculture and Healthcare, 6, 21.

[28] Sintayehu, A. and Kassahun, T. (2017) Genotype-by-Environment Interaction and Yield Stability Analysis in Sorghum [Sorghum bicolor (L.) Moench] Genotypes in North Shewa, Ethiopia. Ethiopian Biodiversity Institute, Addis Ababa.

[29] Lule, D., Fetene, M., de Villiers, S. and Tesfaye, K. (2014) Additive Main Effects and Multiplicative Interactions (AMMI) and Genotype by Environment Interaction (GGE) Biplot Analyses Aid Selection of High Yielding and Adapted Finger Millet Varieties. Journal of Applied Biosciences, 76, 6291. https://doi.org/10.4314/jab.v76i1.1

[30] Lubadde, G., Tongoona, P., Derera, J. and Sibiya, J. (2017) Analysis of Genotype by 
Environment Interaction of Improved Pearl Millet for Grain Yield and Rust Resistance. Journal of Agricultural Science, 9, 188. https://doi.org/10.5539/jas.v9n2p188

[31] Kaya, Y., Akcura, M. and Taner, S. (2006) GGE-Biplot Analysis of Multi-Environment Yield Trials in Breed Wheat. Turkish Journal of Agriculture and Forestry, 30, 325-337. 